\title{
The Impact of Organizational Forgetting on Knowledge Management: Evidence from Pharmaceutical Industry in Egypt
}

\author{
Wageeh A. Nafei ${ }^{1}$ \\ ${ }^{1}$ University of Sadat City, Menoufia, Egypt \\ Correspondence: Wageeh A. Nafei, University of Sadat City, Menoufia, Egypt.
}

Received: September 21, 2017

Accepted: October 17, 2017 Online Published: October 24, 2017

doi:10.5539/ibr.v10n11p193

URL: https://doi.org/10.5539/ibr.v10n11p193

\begin{abstract}
Purpose: The purposes of this paper are to determine the impact of Organizational Forgetting (OF) on Knowledge Management (KM) among employees at the Pharmaceutical industry in Egypt.

Design/methodology/approach: Present study is conducted by descriptive-survey method and its population consists of employees at the Pharmaceutical industry in Egypt. 356 standard questionnaires were distributed of which 285 questionnaires $(80 \%)$ were returned. To gather data, KM questionnaire devised by Jakob (2003) and Wiig (2003) and OF questionnaire devised by Fernandez \& Sun, (2009) and Mo shabbeki et al., (2012) are used.

Findings: The research confirmed a conceptual model for OF. Moreover, research results showed that there is a meaningful relationship between OF and KM. Research results also indicate that OF impacts on KM.

Research limitations/implications: Managers should encourage their employees to share their knowledge. Organizational knowledge can be created through individuals' interactions. This study has some limitations. First, this paper just focuses on organizations to find new perspective for the OF literature. Second, because of the scope of this research, interviewees are limited to individuals who have knowledge or take any seminars related to field of this sector. Other sectors must be considered to attain detailed knowledge related to OF because case-specific studies will bring new dimensions to the literature of OF.

Originality/value: First, this study makes a research contribution to the field of OF because studies related to OF mostly consist of conceptual papers. Second, I have introduced two new perspective to the concept of OF through this research paper.
\end{abstract}

Keywords: knowledge management, organizational forgetting

\section{Introduction}

Organizations of different types and sizes face many risks, as they seek to survive in a changing environment (Chong et al., 2009). Perhaps the most dangerous thing facing them is what is known as Organizational Forgetting (OF) which significantly affects the organization's competitiveness. Therefore, organizations are in an urgent need to know the causes and factors affecting them, as well as ways of prevention and treatment. This means that Organizations must manage OF well in order to determine which type of knowledge, whether old or new, must be disposed or retained. In this case, absorption capacity of organizational memory as well as the way of making benefit of it must be taken into account to keep up with constant changes in surrounding environment (Holan et al., 2004).

OF is a metaphor to understand how knowledge decay occurs in organizations (Holan \& Phillips, 2004a, 2004b; Tsang \& Zahra, 2008). However, it has been ignored by the theoretical literature (Holan, 2011; Besanko et al., 2010), yet organizations have an ability to create new knowledge, retain this knowledge and transfer knowledge to the whole organizations (Argote \& Ingram, 2000; Rao \& Argote, 2006) and forgetting is another important perspective because organizations are able to forget knowledge (Easterby-Smith \& Lyles, 2003).

Many studies and applied researches, which tried to identify the OF, have shown that this variable is among the most important factors affecting functional innovation and learning. (Zeng \& Chen, 2010; Esfahani et al., 2012; Mehrabi et al., 2013; Lopez \& Sune, 2013). The challenge of each organization ensures that this knowledge transfers from person to group level and then to organization level and knowledge transferring. Process encounters to failure. This topic, proposes OF (Tabarsi et al, 2012). 
OF has an effective role in organizations (Casey \& Olivera, 2011; Sadeghian et al. 2012). OF is an important component of KM (Zeng \& Yen, 2010; Ghorbanifard et al. 2014).

$\mathrm{KM}$ is one of the most important organizational components which need to establish a system for learning, gathering, stocking and distributing the knowledge inside an organization. Organizational naturally tend to forget (Conklin, 2001).

$\mathrm{KM}$ and $\mathrm{OF}$ are very important subjects for organizations to reach the desired objectives. In this context, our study focuses on the relationship between KM and OF. The study is structured as follows: Section one is introductory. Section two presents the literature review. Section three discusses the research methodology. Section four presents the hypotheses testing. Section five explains the research findings. Research recommendations will take place at section six. Conclusion will be provided at the last section.

\section{Research Theoretical Basics}

\subsection{Organizational Forgetting Concept}

Forgetting is a general process of putting useless and ambiguous knowledge aside (Hedberg, 1981). Forgetting is a process necessary to remove former ideas to accept more recent ideas. Before organizations try for new ideas and thoughts, they should put aside old ideas by revealing their faults (Nystrom \& Starbuck, 1984).

The way to unlearn during an organizational crisis is by removing top managers as a group. This is because top managers are bolstered by previous successes and adamantly cling to their beliefs and perceptions therefore rationalizing their organizations' failures. Change in ownership is often another trigger of forgetting (Markoczy, 1994).

Forgetting is able to add a new and important aspect to our conception on organizational knowledge dynamism although it needs a special broad plan. Forgetting means to put aside old knowledge to create a new room in order to acquire new knowledge before, during and after learning processes. Forgetting has an important impact on effectiveness of organizational learning processes (Holan \& Philips, 2004).

Forgetting means to forget old knowledge to create a new environment to acquire new knowledge during and after learning processes. Also, forgetting has an important impact on the effectiveness of learning processes in the organization (Halen \& Phillips, 2004).

Forgetting has the potential of adding new important dimensions to our mind. Conditions such as environmental disturbance cause existing memory to be a challenge for information management. Therefore, shattering and renewing some parts of organizational memory is necessary. Forgetting is a main part of organizational dynamism and the relationship between $\mathrm{OF}$ and its dynamism is clear and obvious. Furthermore, forgetting play a key role in effectiveness of learning in an organization (De Holan \& Philips, 2003, 2004b).

Forgetting has been studied as an essential process for change management (Akgun, et al., 2007).

Forgetting valuable information, techniques and knowledge of the organization can lead to lose competitive advantages while in some cases (De Holan, 2004; Fernandez, \& Sune, 2009).

OF is critical for three reasons (1) simply being able to create new knowledge in an organization, or transfer needed knowledge from another organization, is not enough. Instances in which new knowledge disappears before it has been successfully transferred to the organization's memory have been documented. Avoiding forgetting acquired knowledge is therefore a critical part of OL (Day, 1994), (2) organizations sometimes forget things that they need to remember. Despite being transferred to memory, organizational knowledge decays over time and critical pieces of organizational knowledge may eventually be forgotten (Darr, et al., 1995), and (3) forgetting is sometimes an organizational necessity, such as when a new dominant logic needs to replace an old one. In this case, a failure to forget prevents new knowledge from being put into practice and reduces organizational effectiveness (Bettis \& Prahalad, 1996, Lyles, 1992).

OF has three contexts (1) researches indicate that creating or transferring knowledge is not enough because knowledge is able to disappear before transmission to long-term memory via documentary (Day, 1994), (2) organizational memory decays over time and knowledge can be forgotten if the memory is not maintained (Holan \& Phillips, 2004a, 2004b; Benkard, 1999, Argote, 1999), and (3) some writers emphasize forgetting is an organizational necessity to adapt organizational changes (Lyles \& Schwenk, 1992; Prahalad \& Bettis, 1986).

OF basically as lack of ability in benefiting organization's knowledge and experiences. In other words, OF is the failure of organization in benefiting learning which have happened in the past (Kransdorff, 1998).

OF is incapability in benefiting knowledge and past experiences of the organization. The most important subject 
which leads organization toward forgetting is inability in learning and spreading it in organization. The lack of applying knowledge as the result of learning, inability of the company in coding and documenting knowledge and not having stimulation to share it are the most important reasons of forgetting knowledge in companies (Synder, \& Cumming, 1998).

OF isn't a lack of organization's ability in learning, sometimes it's necessary for the organization to put its present knowledge aside strategically and knowingly (Othman \& Hashim, 2002).

OF is the intentional or unintentional loss of organizational knowledge at any level (Martin \& Phillips, 2003).

$\mathrm{OF}$ is a concept of numerous and varied effects negatively and positively. It may be an intentional forgetting which seeks change acquisition, re-acquisition of knowledge, and abandonment of unneeded knowledge by the organization or in other words, reconstructing some parts of organizational memory. It is a positive loss of organizational knowledge (Holan et al., 2004).

OF lead to increase competition and to eliminate unfruitful elements of knowledge (Holan, 2004).

OF might be unintentional in terms of losing part of the knowledge. Therefore, an organization would become unable to carry out some of the activities which it has been able to do previously. This kind of forgetting is often detrimental to the organization as it happens when the Organization is unable to retain a portion of new knowledge in its own memory system. OF is the voluntary or involuntary loss of organizational knowledge. In other words, OF is loss of organizational knowledge voluntary or involuntary which can lead to changes in the organization capabilities (Halen \& Phillips, 2004).

$\mathrm{OF}$ is the basic need for learning new organizational knowledge. This kind of forgetting requires design and time. Organizational performance can be a direct or indirect function of OF. An organization will not learn new knowledge without forgetting previous knowledge (Holan, Philips \& Lawrence, 2004).

OF includes voluntary or involuntary loss of organizational knowledge can lead to change in organizational capabilities (Moshbeki, et al 2007).

OF is an important phenomenon in organizations. One strategy of successful managers for achieving and keeping competitive priority is paying attention to knowledge capitals of their staff. OF can be explained as losing organizational knowledge (intentional or accidental) (Lin \& Kuo, 2007).

OF isn't a lack of ability in learning organizational subjects, but forgetting is a process which happens after learning. It means that an organization first learn knowledge and then forgets it knowingly or unknowingly. OF is the outcome of inter organizational and intra organizational actions in which an organization loses a part of the organization's present knowledge aware or unaware. This knowledge includes some cases such as skills, methods, processes, experiences, documents and techniques being used in the organization. OF is the consequence of a complex of activities which could have root in inter organizational and intra organizational actions and decisions. Organizations should look at OF systematically, aware and with plan to finally achieve some positive results (Besanko, et al., 2007).

OF has been studied mainly from two standpoints. The first standpoint sees accidental or unwanted forgetting as a degradation of the stocks of organizational knowledge. The second standpoint considers forgetting as an intentional process of unlearning preceding organizational learning (Fernandez \& Sune, 2009).

$\mathrm{OF}$ is a powerful tool for the management of organizational knowledge by gaining appropriate knowledge and discarding the inappropriate ones. OF is necessary in organizations regarding to the turbulent environment (Jiang, et al., 2010; Bagherzadeh et al, 2010).

OF is the process of transformation from old to new knowledge within the organization (Jiang, et al., 2010).

Although the concept of OF is easy to understand, but it is not recognized well how its mechanism occurs. As OF can effect on organization competitiveness, organization needs processes to ensure that whether knowledge it is forgotten and whether knowledge is useful, it is not forgotten (Hosseini et al, 2010).

$\mathrm{OF}$ is a changing learning process and learning in organizational memory, one process of leaving deliberated memory and a process of destroying and rebuilding some parts of organization. In last years the OF took attention of many researchers (Jian \& fu, 2010).

OF often leads a great amount of expenses on the organization and many countries spend a lot of sources annually to gain knowledge and information (Ozdemir, 2010).

$\mathrm{OF}$ is the challenge for managers in the new age of business. The most important subject which leads to the forgetfulness, inability to obtain and disseminate learning organization. Failure to apply the knowledge gained 
from learning disabilities to participate in coding and documentation, and lack of motivation for sharing knowledge, it is the most important OF (Saynder \& Keming, 1998; Jalali \& Khosravani, 2010).

OF is the organization's inability to accomplish some of the activities it was previously accomplishing, because of losing some of its organizational knowledge which would considerably affect its competitiveness (Moshabbeki et al., 2011).

$\mathrm{OF}$ is removing routines and understanding this subject that these routines would not be useful for a long time and create problems towards learning more needs of organization. OF includes process that organizational delete old regulations and behaviors by them and create opportunity for new knowledge (Akhavan and et al, 2011).

OF has been examined as loss of organizational knowledge which is not planned or intended (Easterby-Smith \& Lyles, 2011).

$\mathrm{OF}$ is the loss of gained organizational knowledge intentionally or unintentionally. This depends on absorptive capacity of organizational memory and organization desire to become more competitive. Thus, the simple notion of organizational forgetting is the intentional or unintentional loss of organizational knowledge. This significantly affects the organization's status and competitiveness. OF is the loss of a portion of current organizational knowledge in terms of the methods, processes, expertise, documents and traditional techniques used in the organization (Esfahani et al., 2012).

OF is the loss of retained knowledge (Holland et al., 2004). It is the process of avoiding ancient unnecessary knowledge in order to acquire new knowledge (Besanko et al., 2007).

OF is a purposeful or unintentional loss of knowledge at any organizational level (Fernandez \& Sune, 2009). OF is the process of transformation from old knowledge to new knowledge. In other words, OF means that the organization does consciously or unconsciously lose part of knowledge which has been previously retained (Moshabbeki et al., 2011).

OF is the organization's inability to take advantage of knowledge available in its organizational memory (Esfahani et al., 2012). It is a voluntary or involuntary loss of organizational knowledge. (Jain, 2013).

$\mathrm{OF}$ is an attempt for directing of values, organizational treats by use of changing the subjective structures, mental models, logical structures and main theories that direct treats, (Goudarzvand, 2014).

$\mathrm{OF}$ is an important and vital phenomenon that is not realized well and is not simple same learning (Jena et al, 2014).

OF means throwing away the old routine to accept the new ones. According to this definition, first, it is assumed that forgetting is an essential principle for new learning, and secondly, it has the features of targeted forgetting, thirdly, the new routine is superior to old ones. Finally, to accept that forgetting does not occur after teach (Tsang \& Zahra, 2008; Salvati et al, 2014).

\subsection{Organizational Forgetting Dimensions}

\subsubsection{Targeted Amnesia}

Purposeful OF is a preliminary step to the process of organizational learning, as learning cannot happen unless there is a purposeful forgetting of the new organizational knowledge. Therefore, forgetting is a necessary process for the management of change that is no less important than functional learning in order to achieve the organization's competitive advantage (Zeng \& Chen, 2010). OF can be divided into:

1. Removing old knowledge in the organizational memory deliberately or purposefully, because of being unneeded by the organization or obstacles its development. This can be achieved through the staff efforts (Fernandez \& Sune, 2009; Esfahani et al., 2012).

2. The ability to acquire new and useful knowledge and keep them in the organizational memory, as this leads to the competitive advantage of the organization (HoIan et al., 2004).

\subsubsection{Non-Targeted Amnesia}

This kind of forgetting happens when the organization is unable to retain new knowledge in its memory system. It also happens in terms of losing knowledge stored in organizational memory with the passage of time. In this case, the $\mathrm{OF}$ is unintentional and is often harmful to the organization as it reduces its competitive advantage. (Holan et al., 2004) Unintentional OF can be divided into:

1. Organizational memory deterioration, or in other words forgetfulness of some of the knowledge that has been previously kept in the organizational memory. This does affect the organization's competitiveness. To face this 
problem, the organization incurs substantial costs to develop its forgotten knowledge and regain its competitiveness. (Holan et al., 2004).

2. Inability to retain new knowledge in the organizational memory system. To face this problem the organization incurs substantial costs to add the new knowledge to that existing in the organizational memory. (Holan et al., 2004).

\subsection{Knowledge Management}

Knowledge is an organized combination of tasks, roles, procedures, and information. Organizational knowledge is not related to the organization, but it is related to the individuals who have produced it. Indi viduals' knowledge is the product of social interactions and is rooted in social and cultural conditions. Emphasis on individual kno wledge is as important as organizational knowledge and both focuses to some extent on the nature of the tasks, the level of individual training, motivation and management desire to leave the old tasks and devolve them to lower level employees (Alvani et al,2007).

Knowledge is considered as one of the most important resources of competitive advantage. Increasing the importance of knowledge and intangible assets in the success of organizations on one hand and increasing global competition on the other hand (Akhavan et al, 2011).

In light of the above-mentioned definition, the researcher finds that knowledge in its wider sense constitutes the real wealth for each of the individuals or organizations, and it is a vital tool that helps organizations achieve their goals efficiently and effectively.

$\mathrm{KM}$ is a broad range of activities which is used to manage exchange, create or enhance the intellectual capital in an organization and there is not any collective agreement about what KM is. The Most basic definition of KM is finding a way to create, identify, hunt and distribute organizational knowledge to those people who need it (Abdol Karimi, 2003). KM is the knowledge-based management, connecting people to people and people to information to create competitive advantage (Nonaka, 2007).

$\mathrm{KM}$ is based on the idea that an organization's most valuable resource is the knowledge of its people (National Electronic Library for Health, 2008). KM is understood to be an umbrella term encompassing the many unique but related facets of knowledge-exchange, transfer and uptake among them (Dubois \& Wilkerson, 2008).

$\mathrm{KM}$ is a procedure, process or practice to accomplish process about knowledge, process for knowledge, and process from knowledge which leads to improve the internal and external operation (Alryalat \& Alhawari, 2008).

$\mathrm{KM}$ is a structured process with activities to capture, discover, create, filter, evaluate, store, share and apply knowledge from individuals to advance business processes and meet organization 's objectives and goals (Karadsheh, et al., 2009).

$\mathrm{KM}$ is a systematic and integrative process of coordinating organization wide activities of acquiring, creating, storing, sharing, diffusing and deploying knowledge by individuals and groups, in pursuit of organizational goals. $\mathrm{KM}$ is a human resource management exercise than a technology based discipline. It is not merely state of the art technology used to improve efficiency of the knowledge. Rather it is an exercise about how people can be motivated, best utilize their knowledge, experiences and enhance the creativity by using state of the art technology (Nonaka, 2007; Tahir, et al., 2010).

From the above-mentioned definitions, the researcher notice that there is no universally accepted definition of KM, most are extremely similar. In light of the abovementioned facts, the researcher finds that KM is a set of interrelated activities, integrated and related knowledge in terms of creation, acquisition, organization, distribution and use by all employees of the organization.

KM includes five main stages, a process of knowledge creation, knowledge acquisition, knowledge organization, knowledge distribution, and use of knowledge. This can be illustrated as follows (Wiig, 2003):

1. Knowledge Creation indicates the organization's ability to identify information needs in a scientific manner. Views and experiences are codified in order to bridge the knowledge gap between departments and divisions, in addition to providing data to solve the problems of administrative organization.

2. Knowledge Acquisition is the organization's ability to acquire knowledge, store and keep it in order to use it. This acquisition of knowledge occurs from different sources, such as similar organizations which operate in the same area, the scientific and academic institutes, libraries, the Intranet, and any other sources.

3. Knowledge Organization is the organization's ability to classify knowledge and convert it to useful written materials (knowledge base), using modern technological methods. This contributes to achieving benefits for the 
organization.

4. Knowledge Distribution is the organization's ability to disseminate knowledge to the level of administrative organization, and every individual within each level of an administrative unit, whether by e-mail, meetings, training courses or other.

5. Use of Knowledge is the organization's ability to benefit from knowledge, and its circulation among all employees in order to increase functional skills, and creative abilities, which lead to improved quality of service provided by the organization to its customers.

\section{Methodology}

\subsection{Research Model}

The proposed comprehensive conceptual model is presented in Figure (1). The diagram below shows that there is one independent variable of OF. There is one dependent variable of KM. It shows the rational link between the two types of observed variables i.e. independent and dependent variables. The proposed comprehensive conceptual model is presented in Figure (1).

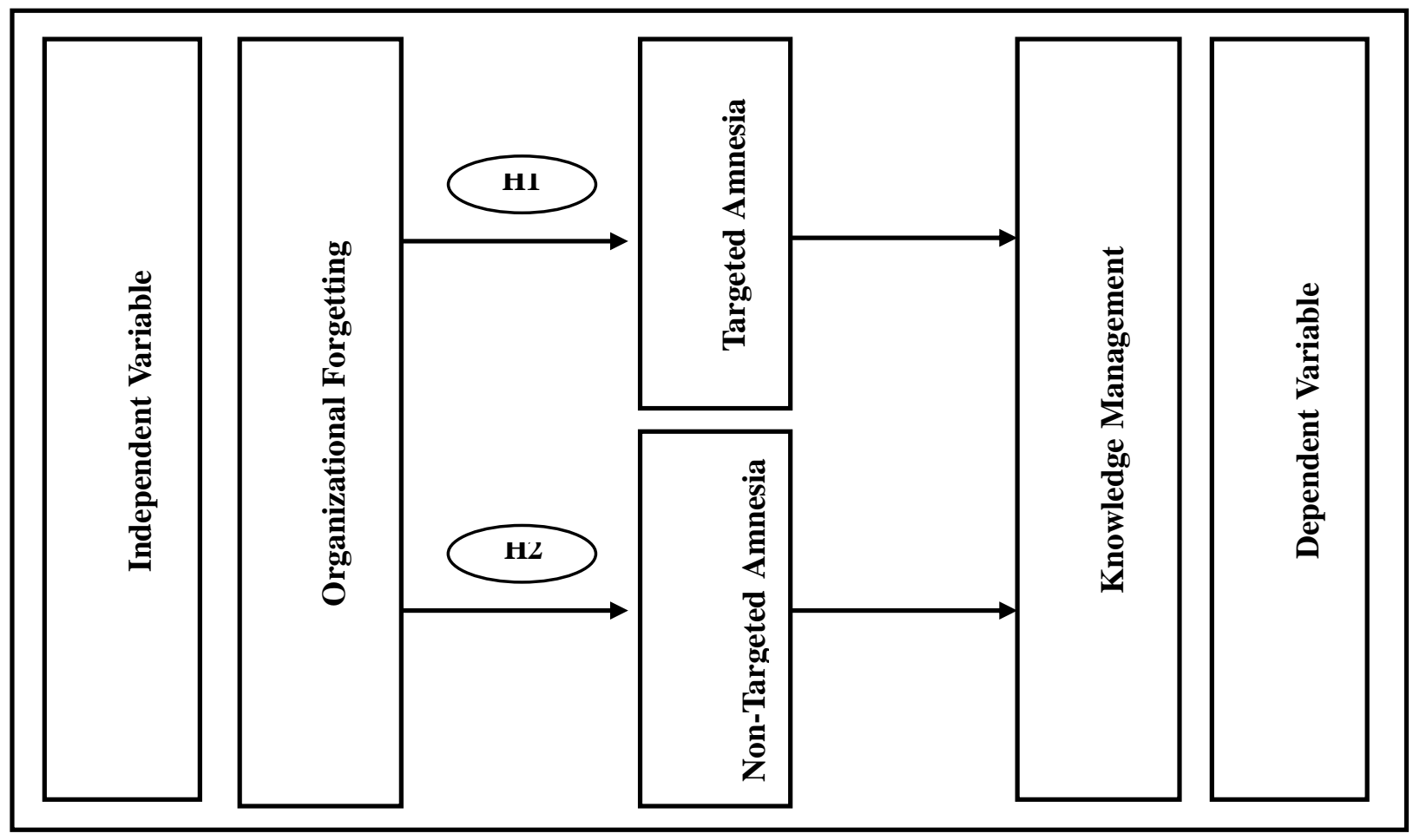

Figure 1. Proposed Comprehensive Conceptual Model

The research framework suggests that OF plays a significant role in affecting KM. In other words, there is a relationship between OF and KM. So, investigating the relationship between OF and KM is attractive to test it at the Egyptian environment.

OF is measured in terms of targeted amnesia and non-targeted amnesia (HoIan et al., 2004; Fernandez \& Sun, 2009; Zeng \& Chen, 2010; Moshabbeki et al., 2011; Esfahani et al., 2012).

$\mathrm{KM}$ as measured consisted of knowledge creation, knowledge acquisition, knowledge organization, knowledge distribution, and use of knowledge (Jakob 2003; \& Wiig, 2003).

\subsection{Research Questions and Hypotheses}

The researcher found the research problem through two sources. The first source is to be found in previous studies, and it turns out that there is a lack in the number of literature reviews that dealt with the analysis of the relationship between OF and KM. This called for the researcher to test this relationship in the Egyptian environment. The second source is the pilot study, which was conducted in an interview with (30) employees in order to identify the relationship between OF and KM.

The researcher found several indicators; notably the important and vital role that could be played by OF. As a result of the discussions given above, the research questions are as follows: 
Q1: What is the nature and extent of the relationship between OF (Targeted Amnesia) and KM at the pharmaceutical industry in Egypt.

Q2: What is the nature of the relationship between OF (Non-Targeted Amnesia) and KM at the pharmaceutical industry in Egypt.

The following hypotheses were developed to test the effect of $\mathrm{OF}$ and $\mathrm{KM}$ at the pharmaceutical industry in Egypt.

H1: OF (Targeted Amnesia) of employees has no statistically significant effect on KM at the pharmaceutical industry in Egypt.

H2: OF (Non-Targeted Amnesia) of employees has no statistically significant impact on KM at the pharmaceutical industry in Egypt.

\subsection{Population and Sample}

The population of the study included all employees at the pharmaceutical industry in Egypt. This sector includes five companies. They are Delta for the pharmaceutical industry, Egyptian International Pharmaceutical Industries (Eipico), Pharma Sweden, Egypt Otsu, and Egyptian Chemicals and drugs. This explains why the population of this study includes 4,783 employees. The random sampling was used for collecting the primary data as it was difficult to get all of the items of the research population because of time limitations. The stratified random sample was used while selecting items from the different categories of employees. The following equation determines the sampling size (Daniel, 1999):

$$
\mathrm{n}=\frac{N \times(Z)^{2} \times P(1-P)}{d^{2}(N-1)+(Z)^{2} \times P(1-P)}
$$

Accordingly, the sample size has become 356 employees at the pharmaceutical industry in Egypt.

Table 1. Distribution of the Sample Size

\begin{tabular}{llccl}
\hline & \multicolumn{1}{c}{ Egyptian Pharmaceutical Companies } & Employees & Percentage & \multicolumn{1}{c}{ Sample Size } \\
\hline 1. & Delta for the Pharmaceutical Industry & 1500 & $31.4 \%$ & $356 \mathrm{X} 31.4 \%=112$ \\
2. & Egyptian International Pharmaceutical Industries (Eipico) & 1833 & $38.3 \%$ & $356 \mathrm{X} 38.3 \%=136$ \\
3. & Pharma Sweden & 850 & $17.8 \%$ & $35617.8 \%=63$ \\
4. & Egypt Otsu & 350 & $7.3 \%$ & $356 \mathrm{X} 7.3 \%=26$ \\
5. & Egyptian Chemicals and drugs & 250 & $5.2 \%$ & $356 \mathrm{X} 5.2 \%=19$ \\
& Total & 4783 & $100 \%$ & $356 \mathrm{X} 100 \%=356$ \\
\hline
\end{tabular}

Source: Personnel Department at Pharmaceutical Industry in Egypt, 2015

Descriptive statistics are used to describe some of the features of the respondents at the pharmaceutical industry in Egypt who participated in the survey. Table (2) provides more detailed information about the sample and the measures.

\subsection{Procedure}

The goal of this study was to identify the relationship between OF and KM at the pharmaceutical industry in Egypt. A survey research method was used to collect data. The questionnaire included three questions, relating to $\mathrm{OF}, \mathrm{KM}$, and demographic information of employees at the pharmaceutical industry in Egypt. Data collection took two months. Survey responses were $80 \%, 285$ completed surveys out of the 356 distributed.

\subsection{Data Collection Tools}

\subsubsection{Organizational Forgetting Scale}

The present study has investigated $\mathrm{OF}$ as an independent variable. The researcher will depend on the scale developed by HoIan et al., 2004; Fernandez \& Sun, 2009; Zeng \& Chen, 2010; Moshabbeki et al., 2011; and Esfahani et al., 2012 in measuring OF, which has been divided into two elements (Targeted Amnesia and Non-Targeted Amnesia).

The 19-item scale OF section is based on HoIan et al., 2004; Fernandez \& Sun, 2009; Zeng \& Chen, 2010; Moshabbeki et al., 2011; and Esfahani et al., 2012. There were twelve items measuring Targeted Amnesia and seven items measuring Non-Targeted Amnesia. 
Table 2. Characteristics of Items of the Sample

\begin{tabular}{|c|c|c|c|}
\hline & & Number & Percentage \\
\hline \multirow{4}{*}{ 1- Job Title } & Physicians & 120 & $42 \%$ \\
\hline & Nurses & 150 & $53 \%$ \\
\hline & Administrative Staff & 15 & $5 \%$ \\
\hline & Total & 285 & $100 \%$ \\
\hline \multirow{3}{*}{ 2-Sex } & Male & 120 & $42 \%$ \\
\hline & Female & 165 & $58 \%$ \\
\hline & Total & 285 & $100 \%$ \\
\hline \multirow{3}{*}{ 3- Marital Status } & Single & 100 & $35 \%$ \\
\hline & Married & 185 & $65 \%$ \\
\hline & Total & 285 & $100 \%$ \\
\hline \multirow{4}{*}{ 4- Age } & Under 30 & 120 & $42 \%$ \\
\hline & From 30 to 45 & 120 & $42 \%$ \\
\hline & Above 45 & 45 & $16 \%$ \\
\hline & Total & 285 & $100 \%$ \\
\hline \multirow{4}{*}{ 5-Educational Level } & Secondary school & 100 & $35 \%$ \\
\hline & University & 150 & $53 \%$ \\
\hline & Post Graduate & 35 & $12 \%$ \\
\hline & Total & 285 & $100 \%$ \\
\hline \multirow{4}{*}{ 6-Period of Experience } & Less than 5 years & 100 & $35 \%$ \\
\hline & From 5 to 10 & 130 & $46 \%$ \\
\hline & More than 10 & 55 & $19 \%$ \\
\hline & Total & 285 & $100 \%$ \\
\hline
\end{tabular}

The survey form is used as the main tool for data collection in measuring OF at the pharmaceutical industry in Egypt. Responses are categorized using a 5-point Likert Scale for each statement, ranging from (1) "very ineffective", (2) "ineffective", (3) "neither effective nor ineffective", (4) "effective", and (5) "very effective".

\subsubsection{Knowledge Management Scale}

The researcher will depend on the scale developed by Jakob (2003) and Wiig (2003) in measuring KM, which has been divided into five main components (knowledge creation, acquisition, organization, distribution, and use of knowledge).

This measure consists of 25 statements: five statements for knowledge creation, five statements for knowledge acquisition, five statements for knowledge organization, five statements for knowledge distribution, and five statements for use of knowledge. The survey form has been used as a key tool to collect data to measure KM at the Pharmaceutical industry in Egypt.

KM has been measured by the five- item scale of Likert of agreement or disagreement where each statement has five options.

The informant should select the answer that suits his choice, where (5) indicates full agreement while (1) indicates full disagreement, with neutral degrees in- between.

\subsection{Data Analysis}

For purposes of the statistical analysis and hypotheses testing, the researcher has employed the following methods:

1. The Alpha Correlation Coefficient (ACC), which aims at verifying the degree of reliability in the scale of OF and KM.

2. The Multiple Regression Analysis (MRA), which aims at verifying the type and strength of the relationship between $\mathrm{OF}$ as independent variables and $\mathrm{KM}$ as a dependent variable.

3. The statistical testing of hypotheses which includes F- test and T-test which go hand in hand with the MRA. All these tests accompany analysis means which are to be used. They are found in SPSS.

\section{Hypotheses Testing}

\subsection{Evaluating Reliability}

Before testing the hypotheses and research questions, the reliability of OF and KM were assessed to reduce errors of measuring and maximizing constancy of these scales. To assess the reliability of the data, Cronbach's alpha test was conducted.

Table (3) shows the reliability results for OF and KM. All items had alphas above 0.70 and were, therefore, excellent, according to Langdridge's (2004) criteria. 
Table 3. Reliability of OF and KM

\begin{tabular}{|c|c|c|c|}
\hline Variables & The Dimension & $\begin{array}{l}\text { Number of } \\
\text { Statement }\end{array}$ & $\mathrm{ACC}$ \\
\hline \multirow{3}{*}{$\mathbf{O F}$} & Targeted Amnesia & 12 & 0.857 \\
\hline & Non-Targeted Amnesia & 7 & 0.884 \\
\hline & Total Measurement & 19 & 0.711 \\
\hline \multirow{6}{*}{$\mathbf{K M}$} & Knowledge Creation & 5 & 0.915 \\
\hline & Knowledge Acquisition & 5 & 0.653 \\
\hline & Knowledge Organization & 5 & 0.811 \\
\hline & Knowledge Distribution & 5 & 0.856 \\
\hline & Use of Knowledge & 5 & 0.886 \\
\hline & Total Measurement & 25 & 0.925 \\
\hline
\end{tabular}

Regarding Table (3), the 19 items of OF are reliable because the ACC is 0.711. Targeted Amnesia, which consists of 12 items, is reliable because the ACC is 0.857. Non-Targeted Amnesia, which consists of 7 items, is reliable because the ACC is 0.884 . Thus, the internal consistency of OF can be acceptable.

According to Table (3), the 25 items of KM are reliable because the ACC is 0.925 . Knowledge creation, which consists of 5 items, is reliable because the ACC is 0.915 . Knowledge acquisition, which consists of 6 items, is reliable because the ACC is 0.653 . Furthermore, knowledge organization, which consists of 5 items, is reliable because the ACC is 0.811. Knowledge distribution, which consists of 5 items, is reliable because the ACC is 0.856 . Use of knowledge, which consists of 5 items, is reliable because the ACC is 0.886 . Thus, the internal consistency of KM can be acceptable.

Accordingly, two scales were defined, OF (19 variables), where ACC represented about 0.711 , and KM (25 variables), where ACC represented 0.925 .

\subsection{Correlation Analysis}

The researcher calculated means and standard deviations for each variable and created a correlation matrix of all variables used in hypothesis testing. Arithmetic mean and standard de viation values related to dependent and independent variables of this study and correlation coefficients between these variables are given in Table (4).

Table 4. Descriptive Statistics and Correlation Matrix of Constructs

\begin{tabular}{|c|c|c|c|c|c|}
\hline Variables & Mean & Std. Deviation & 1 & 2 & 3 \\
\hline Targeted Amnesia & 3.06 & 0.862 & 1 & & \\
\hline 2. Non-Targeted Amnesia & 3.01 & 0.777 & $0.394^{* *}$ & 1 & \\
\hline 3. Knowledge Management & 3.58 & 0.775 & $0.808^{* *}$ & $0.405^{* *}$ & 1 \\
\hline
\end{tabular}

Note: ** Correlation is significant at 0.01 level

According to Table (4), the first issue examined was the different facets of OF. Among the various facets of OF, those who responded identified the presence of Targeted Amnesia $(\mathrm{M}=3.06, \mathrm{SD}=0.862)$. This was followed by Non-Targeted Amnesia (M=3.01, $\mathrm{SD}=0.777)$.

The second issue examined was the different facets of KM (knowledge creation, knowledge acquisition, knowledge organization, knowledge distribution, and use of knowledge). Most respondents identified the overall $\mathrm{KM}(\mathrm{M}=3.58, \mathrm{SD}=0.775)$.

According to Table (4), OF dimensions have a significant relation with KM. The correlation between OF (Targeted Amnesia) and KM is 0.808. For OF (Non-Targeted Amnesia) and KM, the correlation value is 0.405.

Finally, Table (4) proves that there is a significant correlation between OF and KM. So our hypothesis is supported and it can be said that there is a significant and correlation between OF and KM.

\subsection{Organizational Forgetting (Targeted Amnesia) and KM}

The relationship between OF (Targeted Amnesia) and KM at the pharmaceutical industry in Egypt is determined. The first hypothesis to be tested is:

\section{There is no relationship between OF (Targeted Amnesia) and KM at the pharmaceutical industry in Egypt.}

Table 5 proves that there is a relationship between OF (Targeted Amnesia) and KM at significance level of 0,000.

As a result of the value of $\mathrm{R}^{2}$, the 12 independent variables of Targeted Amnesia can explain $76 \%$ of the total differentiation in KM level. For the results of a structural analysis of the MRA, the direct effect of OF (Targeted Amnesia) and KM is obtained. Because MCC is 0.872 , it is concluded that there is enough empirical evidence to reject the null hypothesis. 
Table 5. MRA Results for OF (Targeted Amnesia) and KM

\begin{tabular}{|c|c|c|c|}
\hline $\begin{array}{l}\text { The Variables of OF } \\
\text { (Targeted Amnesia) }\end{array}$ & Beta & $\mathbf{R}$ & $\mathbf{R}^{2}$ \\
\hline 1. The possibility of change lies in the cognitive abilities of workers. & $0.086^{*}$ & 0.116 & 0.013 \\
\hline $\begin{array}{l}\text { 2. The possibility of change lies in the laws and regulations that govern } \\
\text { work in the organization. }\end{array}$ & 0.060 & 0.490 & 0.240 \\
\hline $\begin{array}{l}\text { 3. There is relative stability in service delivery methods, in the short } \\
\text { term. }\end{array}$ & $0.142^{*}$ & 0.657 & 0.431 \\
\hline $\begin{array}{l}\text { 4. There is a tendency to continue actions being performed without any } \\
\text { change in working methods. }\end{array}$ & 0.020 & 0.247 & 0.061 \\
\hline $\begin{array}{l}\text { 5. Possibility of change is available in the organizational culture on a } \\
\text { regular basis. }\end{array}$ & 0.086 & 0.326 & 0.106 \\
\hline 6. There is a possibility of change in the organizational structure. & $0.097^{*}$ & 0.665 & 0.442 \\
\hline $\begin{array}{l}\text { 7. The knowledge capacity of workers is utilized in order to make } \\
\text { fundamental changes in the organization. }\end{array}$ & $0.302^{* *}$ & 0.673 & 0.452 \\
\hline 8. Internal innovation is often used to assess or develop services. & 0.022 & 0.605 & 0.366 \\
\hline 9. always walk or consistency on effective ways that lead to success. & $0.246^{* *}$ & 0.766 & 0.586 \\
\hline $\begin{array}{l}\text { 10. The ability to change the working methods of the organization is } \\
\text { available. }\end{array}$ & $0.088^{*}$ & 0.511 & 0.261 \\
\hline 11. Working methods that previously led to failure are avoided. & $0.242^{* *}$ & 0.706 & 0.498 \\
\hline $\begin{array}{l}\text { 12. There is no culture of fear of leaving the old unsuccessful methods } \\
\text { of work. }\end{array}$ & $0.170^{*}$ & 0.323 & 0.104 \\
\hline - MCC & & 0.872 & \\
\hline - $\mathrm{DC}$ & & 0.760 & \\
\hline - Calculated F & & 71.913 & \\
\hline - Degree of Freedom & & 12,272 & \\
\hline - Indexed F & & 1.75 & \\
\hline - Level of Significance & & 0.000 & \\
\hline$* * \mathrm{P}<0.01 \quad * \mathrm{P}<0.05$ & & & \\
\hline
\end{tabular}

\subsection{Organizational Forgetting (Non-Targeted Amnesia) and KM}

The relationship between OF (Non-Targeted Amnesia) and KM at the pharmaceutical industry in Egypt is determined. The second hypothesis to be tested is:

There is no relationship between OS (Non-Targeted Amnesia) and KM at the pharmaceutical industry in Egypt.

As Table (6) proves, the MRA resulted in the R of 0.563 . This means that KM has been significantly explained by the 7 independent variables of OF (Non-Targeted Amnesia).

Furthermore, the $\mathrm{R}^{2}$ of 0.317 indicates that the percentage of the variable interprets the whole model, that is, $32 \%$. It is evident that the seven independent variables justified $32 \%$ of the total factors of KM.

Hence, $68 \%$ are explained by the other factors. Therefore, there is enough empirical evidence to reject the null hypothesis.

Table 6. MRA Results for OF (Non-Targeted Amnesia) and KM

\begin{tabular}{|c|c|c|c|}
\hline $\begin{array}{c}\text { The Variables of OF } \\
\text { (Non-Targeted Amnesia) }\end{array}$ & Beta & $\mathbf{R}$ & $\mathbf{R}^{2}$ \\
\hline 1. External innovation is often adopted to provide or develop services. & 0.093 & 0.346 & 0.119 \\
\hline 2. Losing of knowledge stored in databases leads to serious results. & $0.508^{*}$ & 0.421 & 0.177 \\
\hline $\begin{array}{l}\text { 3. Dates of the training programs of personnel development are often } \\
\text { spaced. }\end{array}$ & $0.597^{* *}$ & 0.133 & 0.017 \\
\hline 4. Knowledge gained by employees from the training programs is not used. & $0.327^{* *}$ & 0.185 & 0.034 \\
\hline 5. Workers who have knowledge often leave the organization unexpectedly. & 0.216 & 0.343 & 0.117 \\
\hline $\begin{array}{l}\text { 6. There is a decrease in the number of times of using the existing } \\
\text { knowledge of workers. }\end{array}$ & 0.004 & 0.417 & 0.173 \\
\hline $\begin{array}{l}\text { 7. Work methods are often changed without drawing on previous } \\
\text { experiences. }\end{array}$ & 0.047 & 0.380 & 0.144 \\
\hline - $\quad \mathrm{MCC}$ & & 0.563 & \\
\hline - $\mathrm{DC}$ & & 0.317 & \\
\hline - Calculated F & & 18.405 & \\
\hline - Degree of Freedom & & 7,272 & \\
\hline - Indexed F & & 2.01 & \\
\hline - Level of Significance & & 0.000 & \\
\hline$* * \mathrm{P}<0.01 \quad * \mathrm{P}<0.05$ & & & \\
\hline
\end{tabular}




\section{Results}

1. There is a statistically significant relationship between OF and KM at the Pharmaceutical industry in Egypt. In other words, there is a relationship between OF (Targeted Amnesia) and KM at significance level of 0,000 . The Twelve independent variables of Targeted Amnesia can explain $76 \%$ of the total differentiation in KM level according to $\mathrm{R}^{2}$. The direct effect of OF (Targeted Amnesia) and KM is obtained because MCC is 0.872. In other words, OF has impact on organizational performance by influencing on KM. This direct impact has been confirmed by results of other researchers (Kransdorff, 1998; Bhatt, 2002; Lehesvitra, 2004; Besanko et al, 2007; Santos-Vijande et al, 2011; Ho, 2011; Lin \& Kuo, 2013).

2. There is a negative relationship between OF and KM at the Pharmaceutical industry in Egypt. The MRA resulted in the $\mathrm{R}$ of 0.563 . This means that $\mathrm{KM}$ has been significantly explained by the seven independent variables of $\mathrm{OF}$ (Non-Targeted Amnesia). The $\mathrm{R}^{2}$ of 0.317 indicates that the percentage of the variable interprets the whole model, that is, $32 \%$. It is evident that the seven independent variables justified $32 \%$ of the total factors of KM. Hence, $68 \%$ are explained by the other factors. In other words, results of this research show that $\mathrm{OF}$ has effect on KM in this organization and has negative effect on organizational performance. The results are consistent with research conducted by Dierickx \& Cool, 1989; De Carolis \& Deeds, 1999; De Holan and Philips, 2003; De Holan and Philips, 2004a, 2004b; Lin \& Kuo, 2007; Ku, 2011; Tabarsa \& Mirzadeh, 2012; Hezarkhani, 2014.

\section{Recommendations}

1. Managers at the pharmaceutical industry in Egypt should develop their KM in order to improve their organizational performance. This improvement will be obtained when learning process had been done through OF.

2. Organizations should attain the level of adequacy in which they are able to forget useless and ineffective knowledge before learning new useful knowledge. OF can bring considerable expenses for organizations but it should be managed in order to be successful in organizational performance improvement. So, OF is a weakness in utilizing previous knowledge and experiences.

3. Managers at the pharmaceutical industry in Egypt should put telling leadership style aside in organizations so that the positive outcomes of strategic OF help organizations reach their policies.

4. Managers at the pharmaceutical industry in Egypt should start presenting appropriate explanation and reinforcing employees and encourage them to do a planned and knowing effort to review their strategic orientations so that employees forget a part of their knowledge for more efficiency of the organization.

5. Managers at the pharmaceutical industry in Egypt should help employees to recognize bad habits, instructions. Deeds, beliefs and values, which are harmful for the effectiveness, by creating mutual relations and cooperation based on trust so that they forget such knowledge before stabilizing and institutionalizing in organizational memory.

6. It is necessary that forgetting process is managed well so that the former information, which is barrier for beneficial changes, removes from organizational memory. So, leaders should give employees the authority to set aside inefficient and old thoughts so that they could apply better new methods.

7. Organizations must undertake effective knowledge management, try to avoid forgetting them, and identify unnecessary knowledge to remove it. This will help maintain the size of organizational memory that leads to the development of employees and competitiveness of the organization.

8. Organizations must manage the processes of learning and forgetting well, because learning is one of the intangible resources that lead to the functional capacity of employees. The organization doesn't learn to increase its capabilities, but also to forget some unnecessary knowledge in order to take into account the size organizational memory and in the case of the acquisition of new and useful knowledge.

9. Organizations must increase the effectiveness of purposeful $\mathrm{OF}$, in terms of removing the old knowledge on the one hand, and the ability to acquire new knowledge on the other, in order to make access to the best knowledge that will help the organization to keep pace with environmental and technological changes and developments. This would result in maintaining competitiveness of the organization.

10. The organization should develop mechanisms which help it avoiding and treating unintentional OF represented in losing of knowledge which previously retained, on the one hand, and the inability to retain new knowledge, on the other. This significantly affects the functional capacities of the organization's employees. 


\section{Conclusion}

Today is the age of changes. KM is important for competitiveness. Hence, due to knowledge dynamism, its keeping becomes more important. Sometimes, organizations are forced to forgetting on order to generate and keep the knowledge to replace a newer learning. The present paper aims ate studying the relationship between $\mathrm{OF}$ and KM. Findings suggest that there is a significant relationship between OF and KM. When the importance of $\mathrm{KM}$ process is added, the importance of $\mathrm{OF}$ is also added.

$\mathrm{KM}$ is one of the most important organizational components which need to establish a system for learning, gathering, stocking and distributing the knowledge inside an organization. In addition to disseminating organizational learning, this system should be able to prevent necessary and fruitful knowledge forgetting on the one hand and to put aside unfruitful knowledge (OF) on the other hand. Despite of needs to develop organizational learning capabilities, studies indicate that organizations do not learn easily.

Overall, when organizations manage their knowledge capacities, organizational learning ground is paved and it is likely to see OF. When organizations can manage OF actively, they will be able to avoid bad habits as well unnecessary and surplus knowledge which would impact on their position against their rivals.

The conclusions of this research are divided into three pivots. The first pivot deals with the conclusions related to cognitive side, the second contains the conclusions related to the business environment, and the third is the conclusions of the application. These conclusions can be dealt with as follows:

\subsection{Conclusions Related to the Cognitive Side}

There is a set of conclusions related to the cognitive side, in general. These conclusions are:

7.1.1. Scarcity of research focusing on investigation and interpretation of the relationship between the variables of current research in the business environment, specifically in the Egyptian organizations.

7.1.2. OF is expressed by a range of organizational dimensions such as (purposeful OF, Unintentional OF) which can be used to measure the level of OF at any organization.

\subsection{Conclusions Related to Business Environment}

Results of the analysis showed the presence of a set of conclusions directly related to the business environment, namely:

7.2.1. OF arises in any regulatory environment in which knowledge is available. Besides, OF plays an important role in influencing the competitiveness of the organization.

7.2.2. The OF is a key factor to create an organizational environment that can be de veloped or degraded. This depends on the OF type whether it is purposeful or unintentional.

7.2.3. Functional learning and innovation are among the factors which may contribute in development or deterioration of various functions within the organization.

7.2.4. Well management the OF process in terms of identifying the type of forgetting, whether purposeful or unintentional, will be reflected in the development or deterioration of various functions within the organization.

7.2.5. Well management of knowledge would help the organization to deal with the competitive environments conditions, on the one hand, and the achievement of organizational objectives on the other.

\subsection{Conclusions Related to Applied Side}

Results of the analysis showed the presence of a set of conclusions related to the applied aspect of the current search, namely:

7.3.1. Purposeful OF has a significant impact on the organization. This indicates that the Egyptian organizations must adhere to OF through (1) removing the unneeded old knowledge in memory (2) the ability to acquire new knowledge and keep them in organizational memory. This leads to reduce deterioration of the capabilities of learning and functional innovation in these organizations.

7.3.2. Unintentional OF has a significant impact on deterioration of functional learning and innovation. This indicates that the Egyptian organizations under study have the obligation to develop a set of mechanisms that help in reducing the spread of this phenomenon of negative results for the organization, namely (1) losing knowledge that has been retained in the organizational memory, (2) inability to retain new knowledge in organizational memory. Facing these problems will help the organization developing the process of functional learning and innovation. 


\section{References}

Abbasi, E., \& Hejazi, Y. (2010). The role of leadership, culture and organizational learning in promotion of Iranian Agricultural Faculties' performance. Quarterly Journal of Research and Planning in Higher Education, 56, 67-79.

Alasoini, T., Heikkila, A., Ramstad, E., \& Ylo“stalo, P. (2007). Enquiry as New Way of Gathering Information in Tykes-Program: Preliminary Results, Finish Ministry of Labour, Helsinki, 55-71, In Workpolitical Journal 2/2007 (in Finnish).

Assink, M. (2006). Inhibitors of disruptive innovation capability: a conceptual model. European Journal of Innovation Management, 9(2), 215-233. https://doi.org/10.1108/14601060610663587

Besanko et al, (2007). Learning-by-doing, organizational forgetting and industry dynamics, acknowledge ${ }^{-}$nancial support from the NSF under Grant No. 0615615, p. (1- 66).

Branzei, O., \& Vertinsky, I. (2006). Strategic pathways to product innovation capabilities in SMEs. Journal of Business Venturing, 21(1), 75-105. https://doi.org/10.1016/j.jbusvent.2004.10.002

Chiva, et al, (2007). Measuring organizational learning capability among the workforce. International Journal of Manpower, 28(3/4), 2007, 224-242.

Chong, et al. (2009). Is the Malaysian telecommunication industry ready for knowledge management $\begin{array}{llll}\text { implementation? Journal of Knowledge Management, } & \text { 13(1), }\end{array}$ https://doi.org/10.1108/13673270910931170

Esfahani, et al, (2012). Studying the Relationship between Organizational Forgetting and Situational Leadership Style (Case of study: Qom's Melli Bank Branches ). Australian Journal of Basic and Applied Sciences, 6(9), 102-108.

Fernandez, V., \& d Sune, A. (2009). Organizational forgetting and its causes: an empirical research. Journal of Organizational Change Management, 22(6), 620-634. https://doi.org/10.1108/09534810910997032

Holan \& Phillips, (2004). Remembrance of Things Past? The Dynamics of Organizational Forgetting, Management. SCIENCE, 50(11), November 2004, 1603-1613. https://doi.org/10.1287/mnsc.1040.0273

Holan et al, (2004). (Managing Organizational Forgetting). MIT Sloan Management Review, 45(2), 45-51.

Jain, (2013). Individual experience and experience working together: Predicting rates of forgetting from knowing who knows what and knowing how to work together, p. (1-30), 2013.

Jiang, et al, (2010). Management of Organizational Forgetting in Construction of Organizational Absorptive Capacity, Project Supported by Humanities and Social Scien c Program of Ministry of Education of Chin, Grant No.: 20090460451), p.(1-6)

López \& Sune, (2013). Turnover-induced Forgetting and its Impact on Productivity. British Journal of Management, 24, 38-53. https://doi.org/10.1111/j.1467-8551.2011.00785.x

Mehrabi, (2013). (An Analysis the cause and effect relationships and finding the structural equation model between all aspects of transformational leadership Organizational Forgetting and the perception of productivity). Reef Resources Assessment and Management Technical Paper; 38, 336-344.

Moshabbeki, et al, (2011). The Impact of Leadership Styles on Organizational Forgetting of Public and Private Hospitals in Tehran Province, 2010. Journal of Health Administration, 14(44), 41-54.

Saunila \& Ukko, (2012). A conceptual framework for the measurement of innovation capability and its effects . Baltic Journal of Management, 7(4), 355-375. https://doi.org/10.1108/17465261211272139

Sepahv, et al, (2014). Investigating And Analyzing The Relationship Between Organizational Commitment And Organizational Learning Capability (Case Study: Yasooj Steel Company). International Journal of Current Life Sciences, 4(2), 278-284, February, 2014.

Valle, et al, (2004). Training practices and organizational learning Capability Relationship and implications. Journal of European Industrial Training, 28(2/3/4), 2004, 234-256.

Zeng \& Chen, (2010). The Relationship between Intentional Organizational Forgetting and Organizational Innovation: The Mediating Effect of Organizational Learning Capability. Management Science, 47, 47-53.

\section{Copyrights}

Copyright for this article is retained by the author(s), with first publication rights granted to the journal.

This is an open-access article distributed under the terms and conditions of the Creative Commons Attribution license (http://creativecommons.org/licenses/by/4.0/). 